\title{
Thymidine phosphorylase enhances reactive oxygen species generation and interleukin-8 expression in human cancer cells
}

\author{
SHO TABATA $^{1,3}$, RYUJI IKEDA ${ }^{3}$, MASATATU YAMAMOTO ${ }^{4}$, TATSUHIKO FURUKAWA ${ }^{4}$, \\ TAKUYA KURAMOTO $^{1}{ }$, YASUO TAKEDA ${ }^{3}$, KATSUSHI YAMADA ${ }^{3}$, MISAKO HARAGUCHI $^{5}$, \\ YASUHIKO NISHIOKA ${ }^{2}$, SABURO SONE ${ }^{1,2}$ and SHIN-ICHI AKIYAMA ${ }^{1}$
}

\begin{abstract}
Departments of ${ }^{1}$ Medical Oncology, ${ }^{2}$ Respiratory Medicine and Rheumatology, Institute of Health Biosciences, The University of Tokushima Graduate School, Tokushima 770-8503; Departments of ${ }^{3}$ Clinical Pharmacy and Pharmacology, ${ }^{4}$ Molecular Oncology, ${ }^{5}$ Biochemistry and Molecular Biology, Graduate School of Medicine and Dental Sciences, Kagoshima University, Kagoshima 890-8544, Japan
\end{abstract}

Received December 22, 2011; Accepted February 21, 2012

DOI: $10.3892 /$ or.2012.1887

\begin{abstract}
Thymidine phosphorylase (TP) is an angiogenic factor that plays a pivotal role in tumor angiogenesis. Various kinds of solid tumors express TP and high TP activity is correlated with microvessel density. We have previously reported that TP enhances interleukin-8 (IL-8) expression in KB human epidermoid carcinoma cells. In this study, TP was shown to be involved in enhanced expression of IL-8 in EJ human bladder cancer cells and Yumoto human cervical cancer cells as well as KB human epidermoid carcinoma cells. The enzymatic activity of TP was required for the enhanced expression of $I L-8$. A degradation product of thymidine was implicated in the enhanced expression of $I L-8$. TP augmented reactive oxygen species (ROS) generation in KB and Yumoto cells, and the enzymatic activity of TP was again required for the generation of ROS. An antioxidant, N-acetylcysteine (NAC), attenuated the generation of ROS and $I L-8$ mRNA expression in $\mathrm{KB}$ and Yumoto cells, and $\mathrm{H}_{2} \mathrm{O}_{2}$ increased $I L-8$ mRNA expression in Yumoto cells, suggesting that ROS generated by TP caused the increased expression of $I L-8$ mRNA. Since TP also reduced cellular glutathione levels and transcription of $\gamma$-GCS in KB cells, the TP-induced augmentation of ROS
\end{abstract}

Correspondence to: Dr Shin-Ichi Akiyama, Department of Medical Oncology, Institute of Health Biosciences, University of Tokushima Graduate School, Kuramoto-cho 3-18-15, Tokushima 770-8503, Japan E-mail: akiyamas@clin.med.tokushima-u.ac.jp

Abbreviations: TP, thymidine phosphorylase; IL-8, interleukin-8; ROS, reactive oxygen species; NAC, N-acetylcysteine; HO-1, hemo oxygenase-1; DR, 2-deoxy-D-ribose; $\gamma$-GCS, $\gamma$-glutamylcysteine synthetase

Key words: thymidine phosphorylase, interleukin-8, reactive oxygen species, thymidine phosphorylase inhibitor, 2-deoxy-D-ribose may be partially attributed to the decreased glutathione. Our findings suggest that thymidine-derived sugars enhanced ROS generation and consequently increased IL-8 expression.

\section{Introduction}

Thymidine phosphorylase (TP), an enzyme involved in pyrimidine catabolism, is identical with an angiogenic factor, platelet-derived endothelial cell growth factor (PD-ECGF) (1). TP is overexpressed in various tumors and plays an important role in angiogenesis, tumor growth, invasion and metastasis (2). The enzymatic activity of TP is required for the angiogenic effect of TP (3). A novel, specific TP inhibitor, TPI, inhibits angiogenesis induced by TP in KB/TP cells (human $\mathrm{KB}$ epidermoid carcinoma cells transfected with $T P$ cDNA), as well as growth and metastasis of $\mathrm{KB} / \mathrm{TP}$ cells in vivo $(4,5)$.

2-Deoxy-D-ribose (DR), one of the degradation products of thymidine generated by TP activity, has both angiogenic and chemotactic activity (6). Both DR and TP inhibit a hypoxiainduced apoptotic pathway (7). These findings suggest that DR is a downstream mediator of TP function. 2-Deoxy-L-ribose, a stereoisomer of DR, inhibits the promotion of angiogenesis, tumor growth and metastasis by TP $(8,9)$. Recent evidence suggests that DR affects endothelial cell migration through activation of the integrin downstream signaling pathway (10). Rapamycin completely abrogates DR-induced endothelial cell migration and angiogenesis, correlating with a blockade of DR-induced p70S6 kinase activation in endothelial cells (11). Thymidine-derived DR and deoxy-D-ribose 1-phosphate (DR1P) are enzymatically converted to 2-deoxy-D-ribose 5-phosphate (DR5P) (12). Bijnsdorp et al observed that DR1P and DR5P accumulate at high levels in TP-overexpressing cells and DR is extensively secreted by these cells (13).

Brown and Bicknell inferred that DR may be an important energy source under hypoxic conditions (14). Brown et al also reported that TP overexpression in cells treated with thymidine induces hemo oxygenase-1 (HO-1), a classical cellular 
oxidative stress marker (15). Although our results (4) and many reports from other laboratories suggest that TP is pivotal for tumor progression, the molecular basis for the induction of reactive oxygen species (ROS) and angiogenic factors by TP is not completely understood.

In this study, we indicate that TP activity is required for the enhanced ROS generation and $I L-8$ mRNA expression in human cancer cells and agents which inhibit TP activity are strong candidates for new anticancer drugs.

\section{Materials and methods}

Chemicals and cell culture. NAC was obtained from SigmaAldrich. $\mathrm{H}_{2}$ DCF-DA was obtained from Molecular Probes. KB (human epidermoid carcinoma), EJ (human bladder cancer), Yumoto (human cervical carcinoma), THP-1 (human monocyte) and MCF-7 (human breast carcinoma) cells were grown in DMEM (Nissui Seiyaku Co.) containing $10 \%$ calf serum, $2 \mathrm{mM}$ glutamine and $100 \mathrm{U} / \mathrm{ml}$ of penicillin at $37^{\circ} \mathrm{C}$ in a $5 \% \mathrm{CO}_{2}$ humidified atmosphere. The medium was changed to fresh serum-free media before experiments.

Transfection of TP/PD-ECGF cDNA into KB cell. TP/ PD-ECGF full-length cDNA plasmid, TP/PD-ECGF mutant plasmid (L148R, Leu-148 $\rightarrow$ Arg) (3) or the empty vector was transfected into KB cells by electroporation (16). After selection with geneticin, expression of TP in each clone was determined by immunoblot analysis using an anti-TP monoclonal antibody as described (17). A TP-positive clone (KB/ $\mathrm{TP}$ cells) and a control vector-transfected clone (KB/CV cells) were used for further analyses.

Immunoblot analysis. Samples were subjected to 6 or $12.5 \%$ sodium dodecyl sulfate polyacrylamide gel electrophoresis (SDS-PAGE) according to the method of Laemmli (18). Gel proteins were electrophoretically transferred onto polyvinylidene difluoride membranes (Immobilon-P transfer membrane; Millipore) using the Bio-Rad Transblot SD apparatus (19). The membrane was treated with blocking buffer containing $3 \%$ skimmed milk, $350 \mathrm{mM} \mathrm{NaCl}, 10 \mathrm{mM}$ Tris- $\mathrm{HCl}(\mathrm{pH} 8.0)$ and $0.05 \%$ Tween-20 for $1 \mathrm{~h}$ and incubated with the indicated primary antibody overnight at $4^{\circ} \mathrm{C}$. Following 4 washes, the membrane was incubated with a secondary antibody in the buffer for $1 \mathrm{~h}$ at room temperature. The membrane was then washed and developed using enhanced chemiluminescence western blotting detection system (Amersham Pharmacia). Primary antibodies against HO-1 (Santa Cruz Biotechnology), $\alpha$-tubulin (Calbiochem) and $\beta$-actin (Santa Cruz Biotechnology) and HRP-conjugated secondary antibodies (Amersham Pharmacia) were used.

Reverse transcription-polymerase chain reaction (RT-PCR). Total cellular RNA was extracted from cells using the TRIzol reagent according to the manufacturer's instructions (Invitrogen). RT-PCR was performed using the SuperScript One-Step RT-PCR system and gene-specific primers according to the instructions of the manufacturer (Invitrogen). Reaction mixtures containing total RNA (500 ng of each), $0.2 \mathrm{mM}$ dNTPs, $0.2 \mu \mathrm{M}$ of each primer and an enzyme mixture composed of SuperScript II RT, Platinum Taq DNA polymerase and $1 \mathrm{X}$ buffer with $1.2 \mathrm{mM} \mathrm{MgSO}_{4}$ were maintained at $50^{\circ} \mathrm{C}$ for $20 \mathrm{~min}$, then at $94^{\circ} \mathrm{C}$ for $2 \mathrm{~min}$ and $\mathrm{PCR}$ was performed as follows: 30 cycles at $94^{\circ} \mathrm{C}$ for $15 \mathrm{sec}, 55^{\circ} \mathrm{C}$ for $30 \mathrm{sec}$ and $70^{\circ} \mathrm{C}$ for $30 \mathrm{sec}$. The primers for RT-PCRs were designed based on human sequences in GenBank. The forward and reverse primers used for the amplification of IL-8 (1-422; 422 bp; GenBank accession no. NM_000584) fragment were: 5'-ATGACTTCCAAGCTGGCCGTGG-3' and 5'-TTATGAATTCTCAGCCCTCTTC-3'; and those for GAPDH(611-885;275 bp; GenBank accessionno.NM_002046) were: 5'-AGAACATCATCCCTGCCTCTACTGG-3' and 5'-AAAGGTGGAGGAGTGGGTGTCGCTG-3'.

Real-time PCR analysis. One microgram of RNA was reversetranscribed using a first-strand cDNA synthesis kit (ReverTra Ace $\alpha$; Toyobo). Quantitative real-time PCR was performed using SYBR premix Ex Taq (Takara) on the CFX96 ${ }^{\mathrm{TM}}$ RealTime PCR Detection System (Bio-Rad) according to the technical brochure of the company. Quantitative measurements were determined using the $\Delta \Delta \mathrm{Ct}$ method and expression of GAPDH was used as the internal control. Melt curve analyses of all real-time PCR products were performed and shown to produce the sole DNA duplex. A standard curve was prepared for each target gene and PCR efficiency was determined to be in excess of $90 \%$ for all primer sets.

$T P$ activities. Enzyme activity of TP was assayed by the spectrophotometric method. Cell lysates were incubated in a potassium phosphate buffer ( $\mathrm{pH} 6.5)$ and $10 \mathrm{mM}$ thymidine at $37^{\circ} \mathrm{C}$ for $1 \mathrm{~h}$. The thymine formed was quantitated by the absorbance at $300 \mathrm{~nm}$.

Cellular ROS measurement. ROS production was measured using $\mathrm{H}_{2}$ DCF-DA, an uncharged cell-permeable fluorescent probe. Cells were treated with $\mathrm{H}_{2} \mathrm{DCF}-\mathrm{DA}(10 \mu \mathrm{M})$, then washed, re-suspended in PBS and analyzed using a fluorescence microscope (BZ-9000 Biorevo, Keyence) and FACScan (FACSCalibur, BD Biosciences) as previously described (20).

Enzyme linked immunosorbent assays (ELISA) of IL-8. IL-8 concentrations in the culture medium were determined by ELISA (R\&D Systems) according to the instructions of the manufacturer.

RNA interference. TP and scramble siRNA duplexes were purchased from Sigma. The siRNA transfection was carried out using Lipofectamine 2000 (Invitrogen) according to the instructions of the manufacturer.

Determination of cellular glutathione levels. Total glutathione levels were measured using the Total Glutathione Quantification kit (Dojindo Molecular Technologies, Inc.) according to the manufacturer's instructions. Harvested cells were suspended in $80 \mu \mathrm{l}$ of $10 \% \mathrm{HCl}$ and lysed by freezing and thawing. Twenty microliters of 5\% 5-sulfosalicylic acid was added to the lysates and centrifuged at $8000 \mathrm{x}$ g for $10 \mathrm{~min}$ at $4^{\circ} \mathrm{C}$. The supernatant was used to measure glutathione levels. 5,5'-Dithiobis-(2-nitrobenzoic acid) and GSH react to generate 2-nitro-5-thiobenzoic acid. Concentrations of GSH were determined by measuring absorbance at $412 \mathrm{~nm}$. 
A
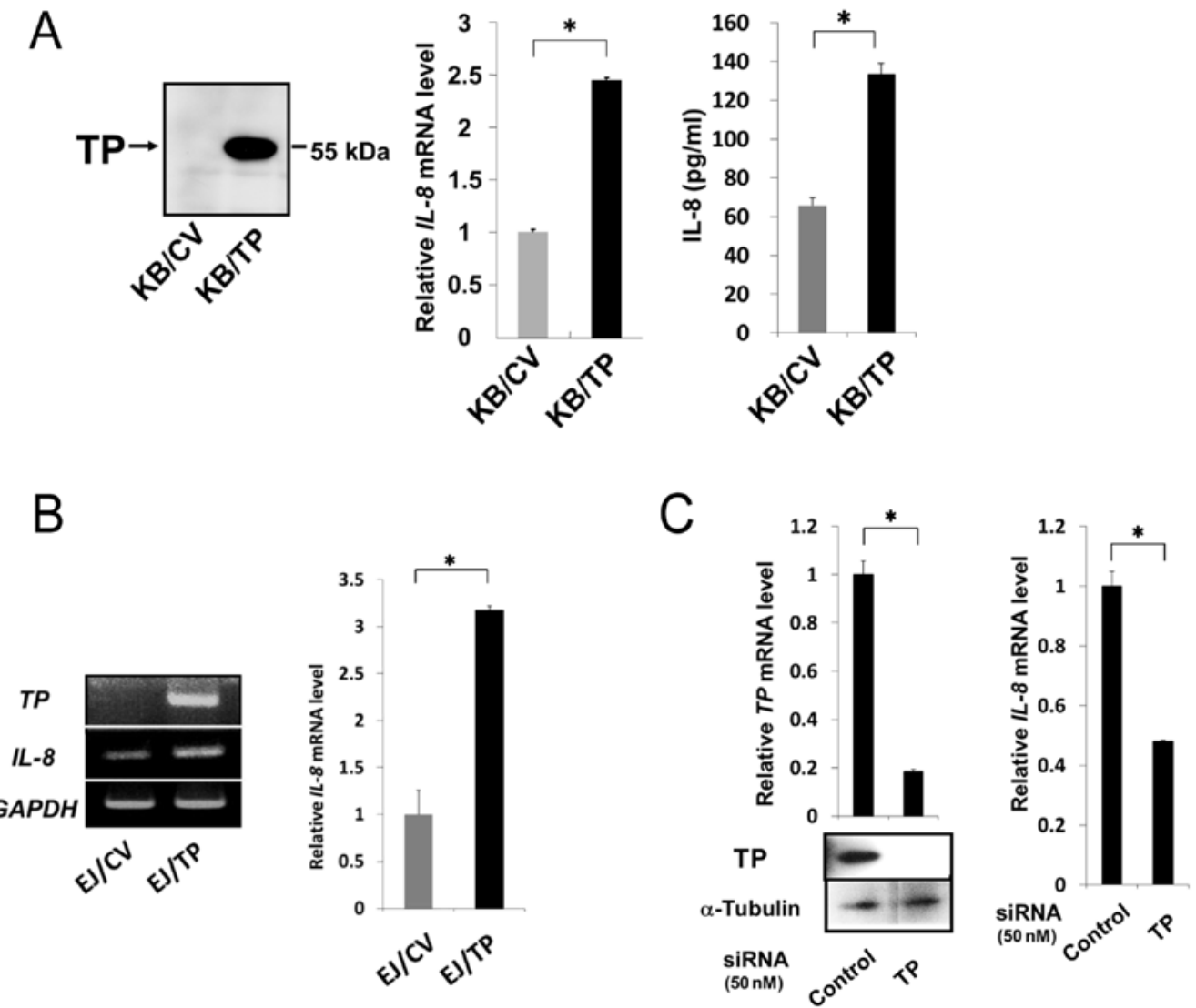

Figure 1. TP induces the expression of IL-8 in cancer cell lines. (A) Immunoblot analysis of TP in KB/CV and KB/TP cells (left panel). TP levels in the cytosol were determined using a monoclonal antibody against TP. $I L-8 \mathrm{mRNA}$ levels in KB/CV and KB/TP cells were measured by real-time PCR and IL- 8 protein levels secreted from the cells were detected by ELISA (right panel). (B) $I L-8 \mathrm{mRNA}$ levels in human bladder cancer EJ/CV and EJ/TP cells were measured by RT-PCR (left panel) and real-time PCR (right panel) to determine the effect of TP on the expression of IL-8. (C) Effect of TP siRNA on the expression of IL-8 in human cervical cancer Yumoto cells. Yumoto cells were treated with control siRNA or TP siRNA, then the effect of the siRNAs on expression levels of $T P$ mRNA and TP was determined by real-time PCR and immunoblotting, respectively (left panel). The levels of $I L-8$ mRNA were measured using real-time $\mathrm{PCR}$ (right panels). Data are represented as mean $\pm \mathrm{SD} .{ }^{*} \mathrm{P}<0.01$.

Statistical analysis. Results were statistically analyzed using the GraphPad Prism v5.0 software. Statistical analyses for all experiments including more than two groups were carried out using one-way ANOVA. Student's t-tests were used for experiments including two groups. Data are presented as the means \pm SD. The differences were considered significant at $\mathrm{P}<0.05$

\section{Results}

Role of TP in the induction of $I L-8$. We have previously reported that expression levels of $I L-8$ mRNA and protein in KB/TP cells, which overexpress TP, were higher than those in $\mathrm{KB} / \mathrm{CV}$ cells that do not express TP (9). In this study, we confirmed that TP is implicated in the expression of $I L-8$ in KB/TP cells (Fig. 1A) and examined whether TP is also involved in IL-8 expression in human bladder carcinoma EJ and human cervical cancer Yumoto cells. TP mRNA was expressed at high levels in EJ/TP cells, but not detected in EJ/CV cells. The expression level of $I L-8$ mRNA in EJ/TP cells was 3.3-fold higher than in EJ/CV cells (Fig. 1B), suggesting that the induction of IL- 8 by TP is not restricted in KB cells. TP siRNA efficiently downregulated expression of TP in Yumoto cells, and suppressed expression of $I L-8$ mRNA in the cells, indicating that the intrinsic TP is also implicated in the expression of $I L-8$ in Yumoto cells (Fig. 1C).

TP activity is needed for the enhanced expression of IL-8. We then examined whether TP activity is required for the enhanced expression of $I L-8$ in KB/TP cells (Fig. 2). KB/CV and $\mathrm{KB} / \mathrm{TP}$ cells were incubated in the absence or presence of thymidine for $48 \mathrm{~h}$, then levels of $I L-8 \mathrm{mRNA}$ in the cells were determined by real-time PCR (Fig. 2A, left panel) and the amount of IL-8 protein secreted from the cells was determined by ELISA (Fig. 2A, right panel). Expression of $I L-8$ mRNA in $\mathrm{KB} / \mathrm{TP}$ cells, but not in $\mathrm{KB} / \mathrm{CV}$ cells, was considerably increased in the presence of thymidine. The secreted IL-8 protein from KB/TP cells was also significantly increased by thymidine.

$\mathrm{KB}$ cells were incubated in the medium without or with $300 \mu \mathrm{M}$ TPI for $48 \mathrm{~h}$, then TP activities in the cytosol were determined photometrically. $I L-8$ mRNA levels in the cells were determined by real-time PCR. TPI at $300 \mu \mathrm{M}$, which is not cytotoxic to KB/TP cells, decreased TP activity in KB/TP cells to $17 \%$ of that in untreated KB/TP cells (Fig. 2B, left panel). TPI at the same concentration significantly decreased the expression of $I L-8 \mathrm{mRNA}$ in KB/TP cells, but not in $\mathrm{KB} / \mathrm{CV}$ cells (Fig. 2B, right panel). Human cancer cell lines, MCF-7 

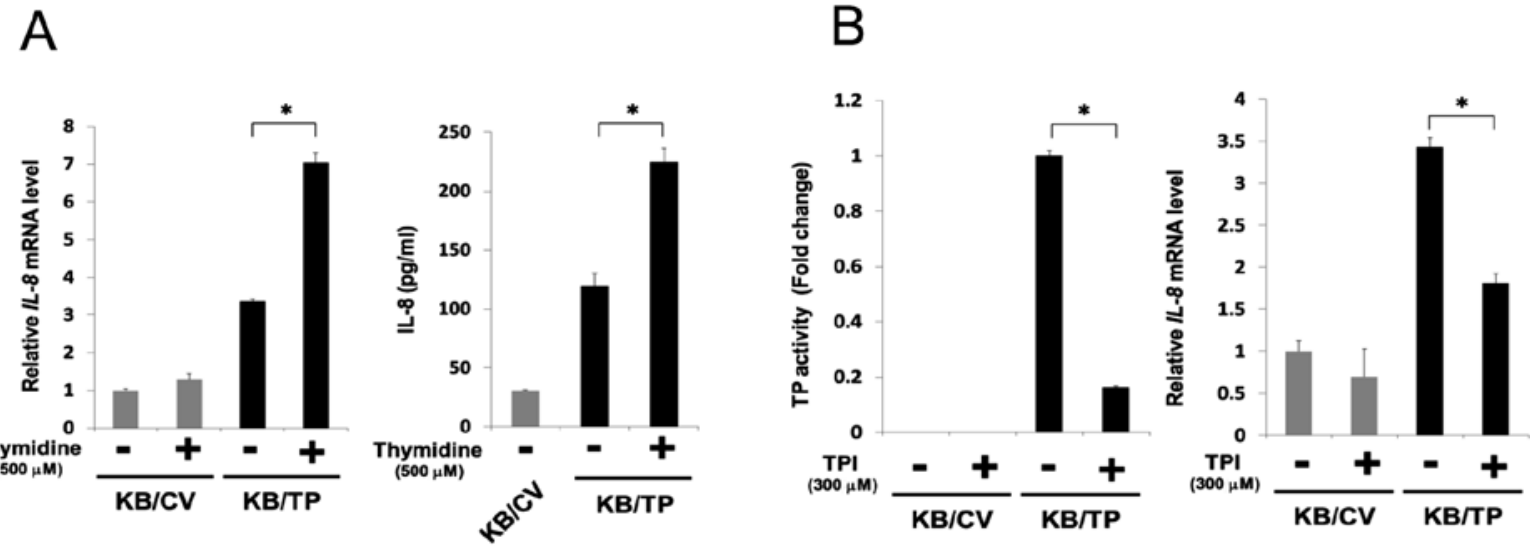

C
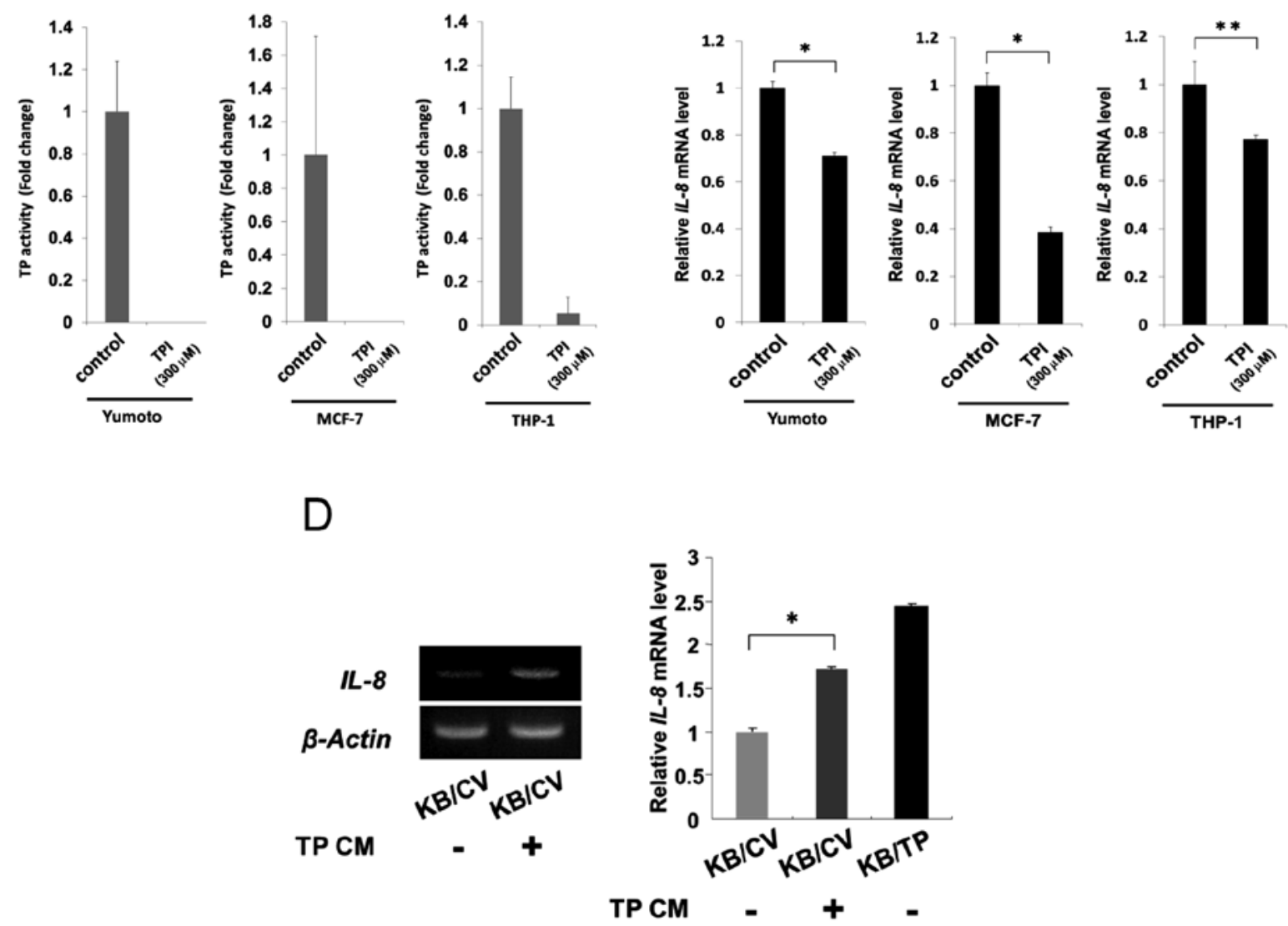

Figure 2. TP activity is required for IL-8 induction. (A) Effect of thymidine on expression of IL-8 in KB cells. KB/CV and KB/TP cells were incubated in the absence or presence of thymidine, then levels of $I L-8$ mRNA in the cells were determined by real-time PCR (left panel) and the amount of IL- 8 protein secreted from the cells was determined by ELISA (right panel). (B) Effect of TPI on $I L-8$ expression in KB cells. KB cells were incubated in the absence or presence of $300 \mu \mathrm{M}$ TPI for $48 \mathrm{~h}$, then TP activities in the cytosol were determined photometrically (left panel). IL- $8 \mathrm{mRNA}$ levels in the cells were determined by real-time PCR (right panel). (C) Effect of TPI on the expression of $I L-8$ mRNA in Yumoto, MCF-7 and THP-1 cells. TPI at $300 \mu \mathrm{M}$, which was not cytotoxic to these 3 cell lines, completely inhibited TP activity in Yumoto and MCF-7 cells and decreased to 5\% of the control level in THP-1 cells. (D) KB/TP cells were cultured in serum-free medium for $24 \mathrm{~h}$ and the medium was used as conditioned medium (TPCM). KB/CV cells were incubated in TPCM for $24 \mathrm{~h}$, then expression levels of $I L-8 \mathrm{mRNA}$ in KB/CV cells and TPCM-incubated KB/CV cells were determined using RT-PCR (left panel) and real-time PCR (right panel). Data are the mean $\pm \mathrm{SD} .{ }^{*} \mathrm{P}<0.01,{ }^{* *} \mathrm{P}<0.05$.

and THP-1 as well as Yumoto, express intrinsic TP. TPI at $300 \mu \mathrm{M}$, which was not cytotoxic to those cells, completely inhibited TP activity in Yumoto and MCF-7 cells and decreased it to 5\% of the control levels in THP-1 cells (Fig. 2C left panel). $I L-8$ mRNA expression in those cells was considerably decreased by the same concentration of TPI (Fig. 2C right panel). These results suggest that TP activity is required for the enhanced expression of $I L-8$ mRNA and thymidine-derived metabolites are involved in the enhanced expression of IL-8 in those cells.

Bijnsdorp et al reported that DR, one of the thymidinederived sugars, is extensively secreted from TP-overexpressing cells (13). When $\mathrm{KB} / \mathrm{CV}$ cells were incubated in conditioned medium of KB/TP cells (TPCM), expression level 
A

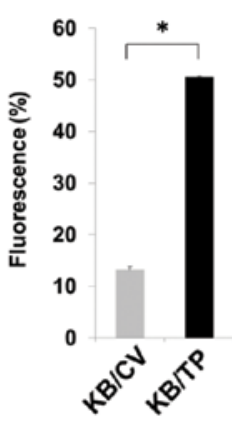

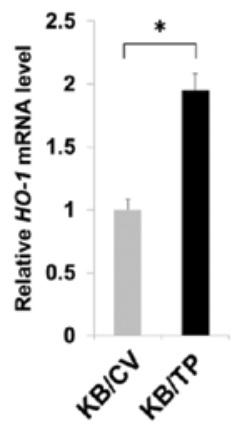

C

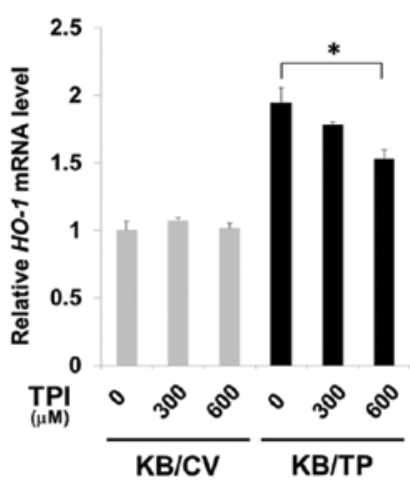

E

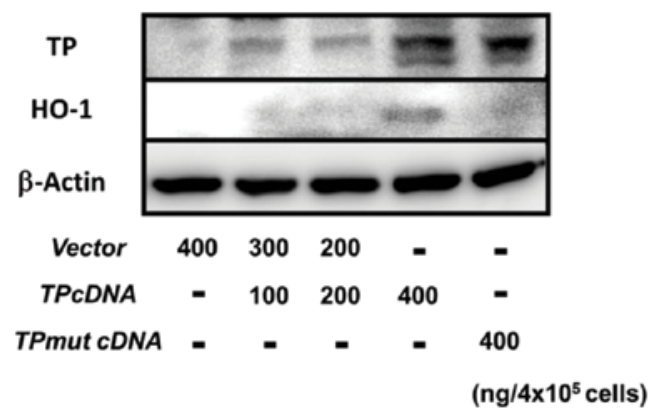

B
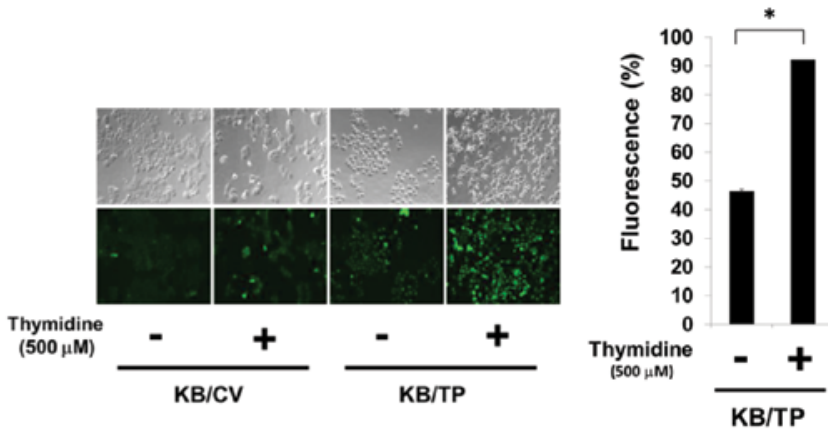

D
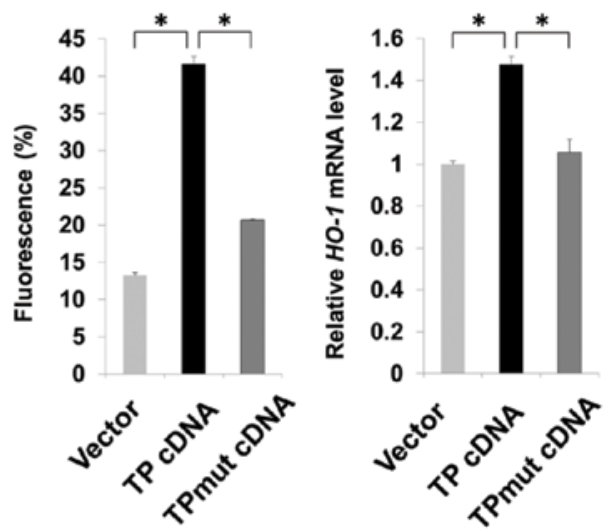

F

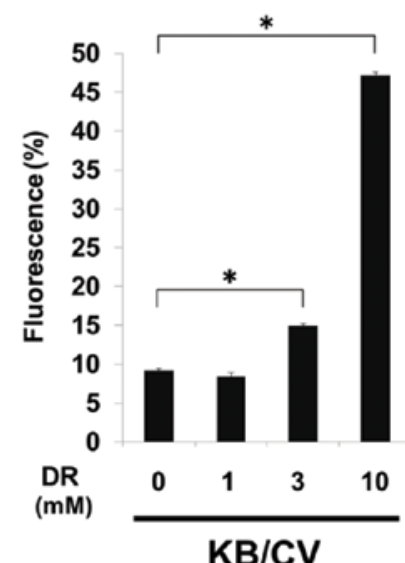

Figure 3. ROS generation by TP. (A) ROS levels in KB/CV and KB/TP cells were determined using $\mathrm{H}_{2} \mathrm{DCF}-\mathrm{DA}$ (left panel). $\mathrm{HO}$-1 mRNA levels in the cells were measured by real-time PCR (right panel). (B) Effect of thymidine on the generation of ROS in KB/CV and KB/TP cells. The cells were incubated in the medium without or with thymidine for $24 \mathrm{~h}$ and ROS in the cells were measured using $\mathrm{H}_{2}$ DCF-DA. Cells expressing ROS were detected using fluorescence microscopy (left panel). ROS in the cells were quantified using FACScan (right panel). (C) $H O-1$ mRNA levels in KB/CV and KB/TP cells in the absence or presence of TPI were determined by real-time PCR. (D) ROS levels in KB cells transiently transfected with empty vector, TP cDNA or TPmut cDNA (400 ng/4x10 5 cells) were detected using $\mathrm{H}_{2}$ DCF-DA (left panel). HO-1 mRNA levels in the cells were determined by real-time PCR (right panel). (E) HO-1 expression augmented by TP in KB cells. To examine the effect of transiently expressed TP, KB cells were transfected with different amounts of TP cDNA or TPmut cDNA (400 ng/4x105 cells) and the effect of TP on HO-1 expression was investigated using immunoblot analysis. (F) ROS levels in KB cells untreated or treated with DR for $24 \mathrm{~h}$ were detected using $\mathrm{H}_{2}$ DCF-DA (left panel). Data are the mean \pm SD. ${ }^{*} \mathrm{P}<0.01$.

of $I L-8$ mRNA in $\mathrm{KB} / \mathrm{CV}$ cells was significantly increased (Fig. 2D). These results suggested that DR were secreted from $\mathrm{KB} / \mathrm{TP}$ cells in the medium and enhanced $I L-8 \mathrm{mRNA}$ expression in $\mathrm{KB} / \mathrm{CV}$ cells.

ROS generation by TP. TP-overexpressing cells treated with thymidine induced expression of hemo oxygenase-1 (HO-1), a classical marker of cellular oxidative stress (15). We firstly investigated ROS and $H O-1$ mRNA levels in $\mathrm{KB} / \mathrm{CV}$ and $\mathrm{KB} / \mathrm{TP}$ cells using the fluorescent probe $\mathrm{H}_{2} \mathrm{DCF}-\mathrm{DA}$ and real-time PCR, respectively. Expression levels of ROS and HO- 1 mRNA in KB/TP cells were about 5- and 2-fold higher than those in $\mathrm{KB} / \mathrm{CV}$ cells, respectively (Fig. 3A). ROS level in $\mathrm{KB} / \mathrm{TP}$ cells was higher than that in $\mathrm{KB} / \mathrm{CV}$ cells and conside- 
A

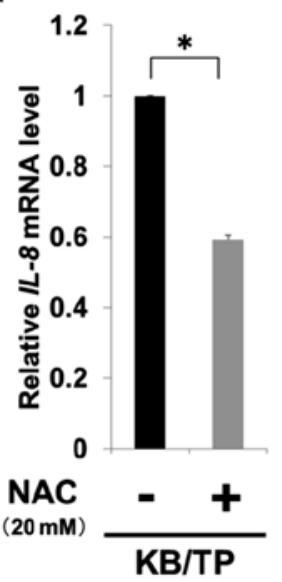

B

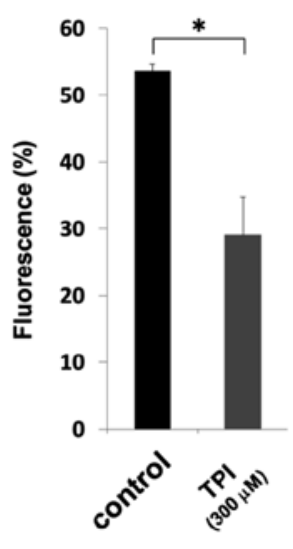

C

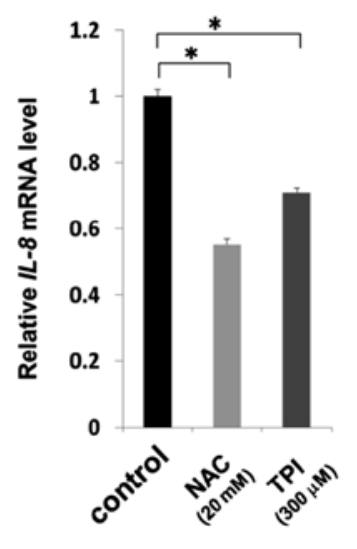

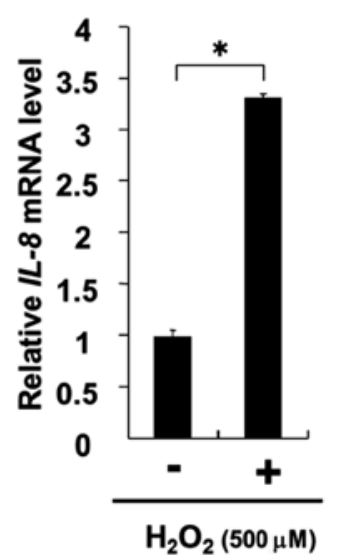

Figure 4. TP-induced ROS results in increased expression of $I L-8$. (A) Effect of N-acetylcysteine (NAC) on $I L-8$ mRNA expression in KB/TP cells. Expression levels of $I L-8$ mRNA were measured using real-time PCR. (B) Effect of TPI and NAC on $I L-8$ mRNA expression and ROS generation in Yumoto cells. Cells were treated with TPI or NAC for $48 \mathrm{~h}$, then the levels of ROS and $I L-8$ mRNA in the cells were measured using $\mathrm{H}_{2} \mathrm{DCF}-\mathrm{DA}$ (left panel) and real-time PCR (right panel), respectively. (C) Effect of $\mathrm{H}_{2} \mathrm{O}_{2}$ on $I L-8 \mathrm{mRNA}$ expression in Yumoto cells. Yumoto cells were incubated in the medium without or with $500 \mu \mathrm{M}$ $\mathrm{H}_{2} \mathrm{O}_{2}$ for $24 \mathrm{~h}$, then $I L-8 \mathrm{mRNA}$ levels were determined by real-time PCR. Data are the mean \pm SD. ${ }^{*} \mathrm{P}<0.01$.

A

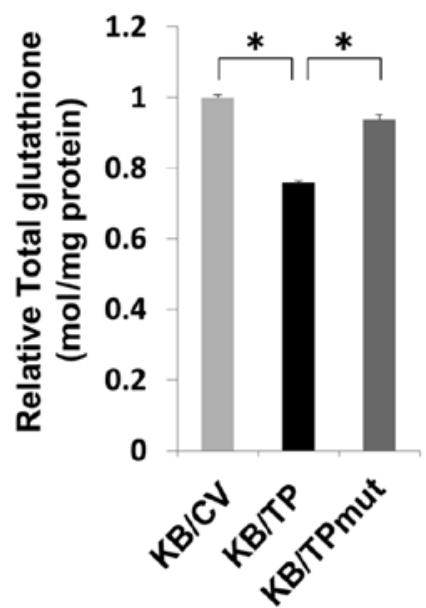

B

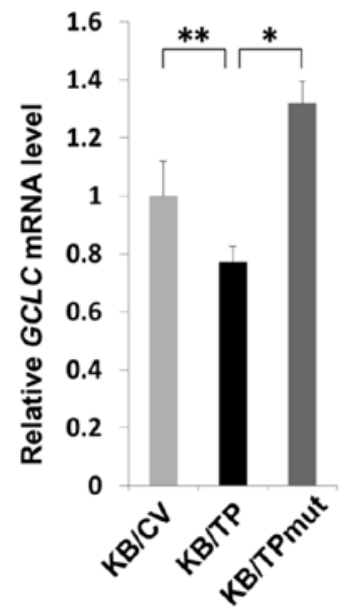

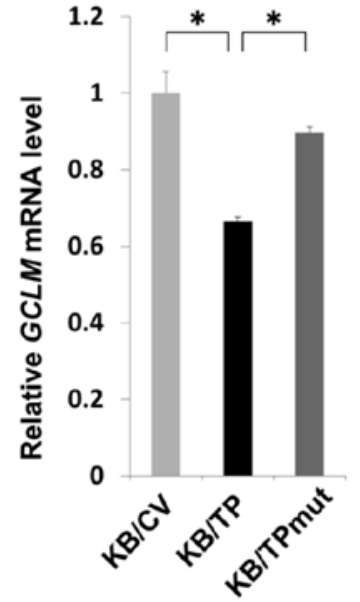

Figure 5. TP decreases the levels of cellular glutathione. (A) The glutathione levels in KB/CV, KB/TP and KB/TPmut cells were determined using the Total Glutathione Quantification kit. (B) mRNA levels of the heavy catalytic (GCLC) and the light regulatory (GCLM) subunits of $\gamma$-glutamylcysteine synthetase in $\mathrm{KB} / \mathrm{CV}$ and $\mathrm{KB} / \mathrm{TP}$ cells measured by real-time PCR. Data are the mean $\pm \mathrm{SD}$. ${ }^{*} \mathrm{P}<0.01,{ }^{* *} \mathrm{P}<0.05$.

rably increased when thymidine was added in the medium (Fig. 3B). Expression level of $\mathrm{HO}-1 \mathrm{mRNA}$ in $\mathrm{KB} / \mathrm{TP}$ cells, but not in $\mathrm{KB} / \mathrm{CV}$ cells, was decreased by TPI (Fig. 3C). We then examined ROS levels in KB cells transiently transfected with empty vector, TP cDNA or TPmut cDNA (400 ng/4x10 5 cells) using $\mathrm{H}_{2} \mathrm{DCF}-\mathrm{DA}$ (Fig. 3D, left panel). $\mathrm{HO}-1 \mathrm{mRNA}$ and protein levels in the cells were also determined by real-time PCR (Fig. 3D, right panel) and immunoblot analysis (Fig. 3E), respectively. ROS and $\mathrm{HO}-1$ levels in $\mathrm{KB}$ cells transiently transfected with TP cDNA were higher than those in KB cells transfected with empty vector or TPmut cDNA that codes mutant TP lacking the enzymatic activity. ROS level in KB/ CV cells was dose-dependently increased by DR (Fig. 3F). These results indicated that transiently expressed TP enhanced
ROS generation and the enzymatic activity of TP is needed for the enhanced generation of ROS.

TP-induced ROS results in increased expression of $I L-8$. To examine whether TP-induced ROS augmented IL-8 expression, we assessed the levels of $I L-8$ in KB/TP cells treated with an antioxidant, NAC. $I L-8$ mRNA expression in $\mathrm{KB} /$ TP cells was considerably decreased by NAC, suggesting that ROS is involved in the enhanced expression of $I L-8 \mathrm{mRNA}$ in these cells (Fig. 4A). TPI significantly suppressed the levels of ROS and $I L-8$ mRNA in Yumoto cells (Fig. 4B). NAC also decreased $I L-8$ mRNA expression in Yumoto cells (Fig. 4B, right panel). $\mathrm{H}_{2} \mathrm{O}_{2}$ at $500 \mu \mathrm{M}$ increased $I L-8$ mRNA levels up to 3.3-fold in Yumoto cells (Fig. 4C). These results suggest that 
TP is involved in the generation of ROS in Yumoto cells which express intrinsic TP and ROS cause the enhanced $I L-8$ mRNA expression in those cells.

TP decreases the levels of cellular glutathione. DR decreased cellular glutathione level in various types of cells $(16,17)$. We examined the glutathione levels in $\mathrm{KB} / \mathrm{CV}, \mathrm{KB} / \mathrm{TP}$ and $\mathrm{KB} /$ TPmut cells. Glutathione levels in $\mathrm{KB} / \mathrm{TP}$ cells were about 20-30\% lower than those in $\mathrm{KB} / \mathrm{CV}$ and $\mathrm{KB} / \mathrm{TPm}$ ut cells (Fig. 5A). $\gamma$-glutamylcysteine synthetase ( $\gamma$-GCS) is the first rate-limiting enzyme of glutathione synthesis. The enzyme consists of two subunits, a heavy catalytic subunit (GCLC) and a light regulatory subunit (GCLM). Both GCLC and GCLM mRNAs in $\mathrm{KB} / \mathrm{TP}$ cells were significantly decreased compared with those in $\mathrm{KB} / \mathrm{CV}$ and $\mathrm{KB} / \mathrm{TPmut}$ cells (Fig. 5B). These results suggested that TP activity is involved in the decreased expression of $\gamma$-GCS and the lowered level of cellular glutathione in $\mathrm{KB} / \mathrm{TP}$ cells.

\section{Discussion}

TP is expressed in various malignant tumors and plays a pivotal role in angiogenesis, tumor growth, invasion and metastasis of TP-expressing tumors (2). DR, one of the thymidine-derived sugars, has similar functions to TP. We have previously suggested that DR is a downstream mediator of TP function $(2,6)$.

Brown et al observed that thymidine upregulated HO-1 in a dose-dependent manner in human bladder carcinoma RT112-TP cells with high TP expression (15). Since cellular oxidative stress is responsible for HO-1 induction, they suggested that TP induced cellular oxidative stress in the cells. In this study, we directly measured ROS levels in KB cells and indicated that TP enhanced ROS generation. TP activity was required for the enhanced generation of ROS and DR also enhanced ROS generation. High concentrations of DR cause ROS generation and lowered intracellular glutathione levels in various cells $(21,22)$.

The level of cellular glutathione in $\mathrm{KB} / \mathrm{TP}$ cells was significantly lower than that in $\mathrm{KB} / \mathrm{CV}$ and $\mathrm{KB} / \mathrm{TPm}$ ut cells (Fig. 5A). Transcription of $\gamma-G C S$ in $\mathrm{KB} / \mathrm{TP}$ cells was also attenuated compared with those in $\mathrm{KB} / \mathrm{CV}$ and $\mathrm{KB} / \mathrm{TPm}$ t cells (Fig. 5B). Glutathione is considered as a main intracellular defense against oxidative stress. Decreased glutathione levels in $\mathrm{KB} / \mathrm{TP}$ cells may be in part implicated in the augmented ROS in the cells.

Brown et al suggested that thymidine catabolism by TP increased carcinoma cell secretion of angiogenic factors induced by oxidative stress (15). We observed that TP augmented the expression of $I L-8 \mathrm{mRNA}$ in human cancer $\mathrm{KB}$, EJ and Yumoto cells. TP activity was again needed to enhance $I L-8$ mRNA expression and DR increased $I L-8$ mRNA expression in $\mathrm{KB} / \mathrm{CV}$ cells that do not express TP. Furthermore, NAC suppressed the increased expression of $I L-8$ mRNA as well as the augmented generation of ROS. These findings indicate that ROS induced by TP enhanced the $I L-8$ mRNA expression. ROS was previously suggested to stimulate cell growth by direct activation of certain redox sensitive transcription factors such as NF- $\mathrm{BB}$ (23). The IL-8 promoter region contains binding sites for the transcription factors, AP-1 (-126 to $-120 \mathrm{bp}), \mathrm{NF}-\kappa \mathrm{B}$ (-80 to $-71 \mathrm{bp}$ ) and NF-IL-6 (-94 to $-81 \mathrm{bp)} \mathrm{(24).} \mathrm{ROS} \mathrm{may} \mathrm{activate} \mathrm{NF- \kappa B,} \mathrm{which}$ is supposed to bind the $I L-8$ promoter and to enhance $I L-8$ gene transcription.

In conclusion, our study demonstrated that the enzymatic activity of TP is required for the enhanced ROS generation and $I L-8$ expression by TP. DR, one of the thymidine-derived sugars, enhanced the generation of ROS in TP-negative $\mathrm{KB} / \mathrm{CV}$ cells. NAC suppressed the enhanced $I L-8 \mathrm{mRNA}$ expression in $\mathrm{KB} / \mathrm{TP}$ cells. The level of cellular glutathione was decreased in TP-overexpressing cells. Decreased glutathione levels in the TP-overexpressing cells may be in part implicated in the augmented ROS generation in the cells, since glutathione is considered as a main intracellular defense against oxidative stress. These findings suggest that ROS generated by thymidine-derived sugars enhance the expression of $I L-8$. TPI inhibited the enzymatic activity of TP and attenuated the TP-induced ROS generation and $I L-8$ mRNA expression in human cancer cells. The results support the notion that compounds that inhibit TP activity, such as TPI, are good candidates for new progressive anticancer agents.

Further study of the molecular mechanisms for the generation of ROS by thymidine-derived sugars and for the enhanced IL-8 expression by ROS will contribute to our understanding of the roles of TP in the malignant progression of tumors.

\section{Acknowledgements}

This study was supported by a Grant-in-Aid for Scientific Research from the Ministry of Education, Culture, Sports, Science and Technology of Japan and the Research Support Foundation of The University of Tokushima and TAIHO Pharmaceutical Co., Ltd.

\section{References}

1. Furukawa T, Yoshimura A, Sumizawa T, et al: Angiogenic factor. Nature 356: 668, 1992.

2. Akiyama S, Furukawa T, Sumizawa T, Takebayashi Y, Nakajima Y, Shimaoka S and Haraguchi M: The role of thymidine phosphorylase, an angiogenic enzyme, in tumor progression. Cancer Sci 95: 851-857, 2004.

3. Miyadera K, Sumizawa T, Haraguchi M, Yoshida H, Konstanty W, Yamada Y and Akiyama S: Role of thymidine phosphorylase activity in the angiogenic effect of platelet derived endothelial cell growth factor/thymidine phosphorylase. Cancer Res 55: 1687-1690, 1995

4. Matsushita S, Nitanda T, Furukawa T, et al: The effect of a thymidine phosphorylase inhibitor on angiogenesis and apoptosis in tumors. Cancer Res 59: 1911-1916, 1999.

5. Takao S, Akiyama S, Nakajo A, et al: Suppression of metastasis by thymidine phosphorylase inhibitor. Cancer Res 60: 5345-5348, 2000.

6. Haraguchi M, Miyadera K, Uemura K, et al: Angiogenic activity of enzymes. Nature 368: 198, 1994.

7. Kitazono M, Takebayashi Y, Ishitsuka K, et al: Prevention of hypoxia-induced apoptosis by the angiogenic factor, thymidine phosphprylase. Biochem Biophys Res Commun 253: 797-803, 1998.

8. Uchimiya H, Furukawa T, Okamoto M, et al: Suppression of thymidine phosphorylase-mediated angiogenesis and tumor growth by 2-deoxy-L-ribose. Cancer Res 62: 2834-2839, 2002.

9. Nakajima Y, Gotanda T, Uchimiya H, et al: Inhibition of metastasis of tumor cells overexpressing thymidine phosphorylase by 2-deoxy-L-ribose. Cancer Res 64: 1749-1801, 2004.

10. Hotchkiss KA, Ashton AW and Schwartz EL: Thymidine phosphorylase and 2-deoxyribose stimulate human endothelial cell migration by specific activation of the integrins $\alpha_{5} \beta_{1}$ and $\alpha_{v} \beta_{3}$. J Biol Chem 278: 19272-19279, 2003. 
11. Seeliger H, Guba M, Koehl GE, et al: Blockage of 2-deoxyD-ribose induced angiogenesis with rapamycin counteracts a thymidine phosphorylase-based escape mechanism available for colon cancer under 5-fluorouracil therapy. Clin Cancer Res 10: 1843-1852, 2004.

12. Hoffee PA: 2-Deoxyribose gene-enzyme complex in Salmonella typhimurium I. Isolation and enzymatic characterization of 2-deoxyribose-negative mutants. J Bacteriol 95: 449-457, 1968

13. Bijnsdorp IV, Azijli K, Jansen EE, et al: Accumulation of thymidine-derived sugars in thymidine phosphorylase overexpressing cells. Biochem Pharmacol 80: 786-792, 2010.

14. Brown NS and Bicknell R: Thymidine phosphorylase, 2-deoxyD-ribose and angiogenesis (Review). Biochem J 334: 1-8, 1988

15. Brown NS, Jones A, Fujiyama C, Harris AL and Bicknell R: Thymidine phosphorylase induces carcinoma cell oxidative stress and promotes secretion of angiogenic factors. Cancer Res 60: 6298-6302, 2000.

16. Potter H, Weir L and Leder P: Enhancer-dependent expression of human kappa immunoglobulin genes introduced into mouse pre-B lymphocytes by electroporation. Proc Natl Acad Sci USA 81: 7161-7165, 1984.

17. Takebayashi Y, Yamada K, Miyadera K, et al: The activity and expression of thymidine phosphorylase in human solid tumours. Eur J Cancer 32A: 1227-1232, 1996.
18. Laemmli UK: Cleavage of structural proteins during the assembly of the head of bacteriophage T4. Nature 227: 680-685, 1970.

19. Andersen JK: Electroblotting of multiple gels: a simple apparatus without buffer tank for rapid transfer of proteins from polyacrylamide to nitrocellulose. J Biochem Biophys Methods 10: 203-209, 1984

20. Tuvdendorj D, Oketani M, Ikeda R, et al: Aspirin induces hepatoma-derived cell apoptosis via a hydrogen peroxidedependent pathway. Hepatol Res 26: 47-54, 2003.

21. Fico A, Manganelli G, Cigliano L, et al: 2-Deoxy-d-ribose induces apoptosis by inhibiting the synthesis and increasing the efflux of glutathione. Free Radic Biol Med 45: 211-217, 2008.

22. Schmidt MM, Greb H, Koliwer-Brandl H, Kelm S and Dringen R: 2-Deoxyribose deprives cultured astrocytes of their glutathione. Neurochem Res 35: 1848-1856, 2010.

23. Brar SS, Kennedy TP, Sturrock AB, et al: NADPH oxidase promotes $\mathrm{NF}-\mathrm{\kappa B}$ activation and proliferation in human airway smooth muscle. Am J Physiol Lung Cell Mol Physiol 282: L782-L795, 2002.

24. Murayama T, Ohara Y, Obuchi M, Khabar KSA, Higashi H, Mukaida $\mathrm{N}$ and Matsushima K: Human cytomegalovirus induces interleukin- 8 production by a human monocytic cell line, THP-1, through acting concurrently on AP-1- and NF- $\kappa \mathrm{B}$-binding sites of the interleukin-8 gene. J Virol 71: 5692-5695, 1997. 